\title{
The Academic Library Nexus
}

Nina W. Matheson

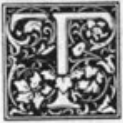

his talk might be considered about documents and their availability. But its topic is really the relationship between data and the recipient, and the library and its institutional information systems. We need to keep in mind that information is not a property of documents, or of bibliographic records, but the relationship between data and the recipient. Increasingly, the burden and the responsibility of libraries in the Information Age is to deal with that relationship.

In her letter of invitation, Lynch proposed that I share with you my vision of the future role of academic libraries. In the course of preparing for this lecture, perhaps in a vain effort to improve my vision, I ran across an anecdote about Winston Churchill that says nearly all I have to say about the future of libraries. After World War II and his stint as prime minister, Winston Churchill was invited to give the commencement address at his old school, Harrow, and decided he ought to oblige. So he went, weathered a lengthy and laudatory introduction, got to his feet and said to the graduating class, "Nevah give up!" and sat down. ${ }^{1}$

I would emulate Mr. Churchill, but I, alas, was asked for a lecture, not an address. An address, according to the current edition of the Random House College Dictionary, is "a statement." A lecture, on the other hand, is a "discourse read . . especially for instruction or to set forth some subject." If I were more like Winston Churchill, I would say that the future role of academic libraries is what we are prepared to make of it in the next three to five years and sit down. As I have few of his talents, for the next thirty minutes you will hear some more or less connected thoughts about the deinstitutionalization of libraries and what we might do in the next three to five years to shape the future role of academic research libraries.

I plan to draw examples from the sciences, including medicine, because of their greater intensity of experimentation and change in information management. But I hope you will look beyond the particulars to the essence, to the application of the principles and concepts to your setting and specialty. Also let me insert here a caveat about the remarks to follow.

These opinions do not in any way, directly or indirectly, reflect any thinking or planning within the National Library of Medicine with respect to the present or future roles of libraries generally, or itself particularly, as a national library. On the other hand, the National Library of Medicine is committed to supporting the development of at least four prototype integrated academic information management systems based on the concepts and principles described in the report prepared by the Association of American Medical Colleges titled, Academic Information in the Academic Health Sciences Center. ${ }^{2}$ Through its grant program, it is also strongly encouraging research and development of a variety of efforts to bring about a paradigm change in the roles of libraries in health information dissemination and management.

It is important to know that the interdisciplinary committee, whose thinking formed the basis of that AAMC report, had in mind no single vision and no single model. Neither the length of the path, the

Nina W. Matheson is special expert consultant, Planning Office, National Library of Medicine, Bethesda, Maryland. This paper, the 1983 Yuri Nakata Lecture, was presented at the University of Illinois at Chicago on November 29, 1983. 
detours, nor the end of the road is known. In many respects, all of us working in information are on a voyage of discovery, and we need to remember what André Gide observed in one of his novels about voyages of discovery: a condition of setting out to find new lands is that you agree to lose sight of the shore for a very long time.

These are very interesting, turbulent, ambiguous, and very disturbing times to be a librarian. One reason is that much information is being deinstitutionalized and dematerialized. Many of the sources for the most up-to-date information have lost their static, immutable qualities and have become interactive and permutable. You don't have to go to a library to read a journal article, and you don't have to copy, cut and paste, and rekey characters to make a new text. Another reason is that communications networks have made possible individualized access to information, independent of institutional, organizational, or professional affiliations. You don't have to be a doctor to have online access to health information or be a broker to see the latest market quotations. A third reason is that because more occupations and activities are perceived as information intensive, it is more apparent that work quality and productivity depend increasingly on work stations that can access and use data from multiple sources. You don't have to have huge data processing centers; you have instead data management tools, the automated office, the wired campus, and the home communication centers. Information appears to be joining food and shelter as one of Maslow's basic needs. A fourth reason is that videodisk technology to store and retrieve text and images in enormous quantity, cheaply, is at hand. We are within a few years of having a physician's working library on a videodisk in his/her office. A fifth reason is the microcomputer and the imperative of computer literacy. No one who expects to do serious professional work in the next five years can be without one at home. It is becoming as basic a tool as the telephone itself.

Most of us here are likely to be well acquainted with the ideas of Bell, Drucker,
Toffler, Naisbett, and Rifkin. We know that there is a total restructuring in progress of who, what, and how information is created, owned, and shared. We librarians, no less than steelworkers, will be out of work unless we, like them, reexamine our basic assumptions and develop new strategies for staying in business. Our situation is not quite as desperate as that stated by James Baker, General Electrics vice-president. At a recent White House conference on productivity, he characterized the choices of American industry to be one of three things: automate, emigrate, or evaporate. But our situation is serious. Libraries are automating, but the key question is what are we automating for. Unfortunately, most of the time, it is to do the same thing better and faster rather than to do new things.

Drucker says in his book Managing in Turbulent Times that public service institutions must "slough off yesterday" through systematic abandonment of certain assumptions and mind-sets. We must think the unthinkable. Drucker gives the social worker as an example. Social workers, he says "will always believe that the failure of efforts to get a family off welfare proves that more effort and more money are needed ... a and cannot accept that they had better stop doing what they had so valiantly failed in continuously over half a century.",3

We must ask ourselves some very hard questions. What have we been failing at that we had better stop doing or do differently? How long have we been trying to get people to come to the library, to use the library? How long have we responded to a request for information by pointing to a bibliographic citation? Why should we think that online catalogs or a bibliographic database search makes information more available? Why do we think handing a person a document provides the answer to a question? Do our solutions really respond to information access problems? Or is it, as some commentators have observed, that libraries have a couple of solutions and make information access problems fit them. We routinely provide access to only our monographic holdings. What about the other two-thirds of the col- 
lections, the serials and documents? Why don't we accept responsibility for providing the same access to what is for most research institutions the most important and critical portions of any collection of materials? Are we shackled to the threeby-five-inch card and what has always been in the card catalog? Is it possible that we should try to put more thought into the unthinkable?

I realize that many share the view that new roles will evolve, that libraries are engaged in an evolutionary rather than a revolutionary process. This is a dangerously passive perspective for our profession. Thomas Kuhn, the eminent historian and philosopher of science, views the transformation of knowledge as a revolutionary process. Once a paradigm is erected, what engages most scientists throughout their careers are mopping up operations. It requires a career of revolt on the part of other scientists to replace or establish the paradigm. The revolt could involve little more than the reconstruction of group commitments among the community of scientists. ${ }^{4}$

What Kuhn says of science clearly applies to social organizations. We know that the library paradigm is changing, but I am not at all sure that we have a group commitment among our profession as to what it should be. In the Medical Library Association, a group I consider entrepreneurial and open to change, the commitment to the concept of integrated systems seems to be coalescing. The tasks that must be performed to transform the concept to a thing that can be kicked and smelled has many of us shivering, with hope as well as fear. The dichotomy was clearly exposed in an exchange at our annual meeting in June between two highly respected members. One member proposed that we librarians adopt the slogan, "If it's information we can manage it." The other thought that was nothing more than an empty slogan, that we are equipped with neither the skills nor the tools, that others own that turf, and that we should stick to doing what we do best-managing libraries.

If the National Library of Medicine initiative is revolutionary in any way, it lies not in the novelty of the concepts or the rightness of the course of action to develop integrated information systems, but in encouraging a handful of institutions to attempt a different paradigm. The first year of NLM support is for institutionwide strategic planning to design a system that will integrate systems, like libraries, with information and files that underpin the work and mission of the academic enterprise. This planning, at four institutions, is led at the senior executive levels, and involves all key senior staff in the health sciences centers. Ideally, the planning will result in an institutional policy, an organizational way of managing, teaching, and working through the use of information systems and support services. Ideally, a different kind of grammar will emerge that can provide a useful way to rearrange our assumptions about what libraries must be. Others have tried earlier to do this. A notable and worthy example is the Hampshire College experiment, about which Robert Taylor wrote eloquently in his book The Making of a Library. ${ }^{5}$ The experiment, to have no physical library but an information center, was ahead of the technology and ahead of the times. What contributed to the failure of the experiment, in Taylor's view, was mainly the fixed notions of the faculty about what a library must be: first, a collection of materials. The environment today is better prepared to work through the concepts of integrated library and information systems. For a growing number of students, faculty, and librarians, databases and files are becoming equivalent to books and journals.

Just as the library profession has yet to commit itself to Kuhn's "career of revolt," so are the CEOs of many of our academic research centers. As an example, I cite Steven Muller, president of John Hopkins University, in a recently published interview. ${ }^{6}$ At the beginning of the interview, he said, "We are in the middle of a revolution. That's a dramatic word, but in this case an unavoidable word, in speaking of the way in which this society produces, disseminates, and consumes information. Teaching institutions are directly exposed to fundamental changes in the way infor- 
mation is generated, disseminated, and absorbed. At a minimum we have to be up-to-date, and at a maximum try even to play some sort of leadership role." Two columns over he stated, "And of course we also have the traditional problems. We have to be vigilant about maintaining the libraries. Always."

The discontinuity between information and libraries that is framed in these two statements is unsettling. It characterizes the paradigm against which some of us must make a "career of revolt."

Given what we know of the past and of the next ten to fifteen years, neither the academic library, nor the profession, is well positioned. The library's assets usually include a large physical plant, a stock of essential materials to support learning, a crucial product (the card catalog), and skilled staff who enable individuals to gain access to the stock. The library profession has a noble history and a mission to serve society. Thomas Cogden could have been talking about librarians when he said, "It's incredible to be in a profession in which nearly everybody could be making more money someplace else. It sorts out the truly greedy, which makes it alot more congenial." Cogden, you might be surprised to learn, was talking about publishers when he made that remark.

However, our assets are undergoing a devaluation process. We have institutionalized information in a facility that is frequently difficult to approach, much less penetrate, in a time when information is transported instead of people. We control a stock of essential materials that can only be used by one person at a time in one way, in an increasingly multiuser interactive environment. We accept full responsibility to provide bibliographic access to only a small portion of the collection, the monographs, when the most dynamic and critical information is carried in the serial literature. Furthermore, the bibliographic files, because they are value-free, are increasingly valueless because they cannot help a user differentiate between the useful and the useless, and this in a time when expert advice is essential to manage the data overload that exists. Perhaps worst of all, librarians, unlike other professional groups, are identified with the place in which they work. Nurses nurse, doctors doctor, professors profess, and lawyers argue outside hospitals, universities, and courtrooms. But librarians are identified, perhaps irrevocably, with the archiving of artifacts, whether books or bibliographic units, rather than the dissemination and uses of knowledge. The fact that storage and retrieval functions are important, fundamental, and enduring is not the issue.

The critical issue for academic libraries and librarianship as a profession is not whether or how soon books will vanish and with them libraries. This is a question on which we should waste little time and less paper. There will likely always be libraries, in fact as well as in concept, with or without books. For example, the field of genetics engineering, the most far-out technology that we have, has libraries of genes, of bits of DNA. These bits are classified and stored for later retrieval and gluing together, to make new forms of life. All computers, even my personal home computer, has a library function: in this case, names and addresses for datafiles. There will, for a long time, be librarians. But the professionalism of the calling is likely to evaporate as the world proceeds to automate, unless we deal in information rather than books or bibliographic units. The critical issue is how we will control the management and distribution of information within institutional networks. Connecting our online bibliographic databases and circulation systems will not suffice for long.

Harbingers of the information world of the year 2000 are arriving daily. One is the announcement from BRS, a major database vendor. BRS has signed contracts with the key publishers of the Englishspeaking world's core medical literature to publish the complete texts of their books and journals online along with sophisticated searching capabilities. The prestigious New England Journal of Medicine, the medical equivalent of the Wall Street Journal, will offer day-of-release access to the current issue, as well as to three years of back issues. Within a short time, BRS expects to distribute videodisks of the 
complete text along with illustrations, figures, and photographs for replay on nearindustrial-grade playback units. This information has yet to make the cover of Time magazine, but it is a signal of a radical change in the course of publishing and will profoundly affect the practice and teaching of medicine as well as the roles of all libraries. As their public release states, "The universe of medical knowledge will now be more readily accessible to everyone, physicians and non-physicians alike .... to everyone concerned with personal health, well being and the issues of medicine and health care. Online medical information systems are a major growth industry in the new information society in which we are living."

Another harbinger is an article by Walter Panko, assistant to the vice-president for academic systems, Baylor School of Medicine, titled "Pathology through the Looking Glass. ${ }^{1 / 8}$ It is a vision of the life in the day of a clinical pathologist in 1997. This excerpt will give you just a little flavor:

Dr. Jones walks into his office and while he slips into his white coat asks, "What's on my schedule today?" The reply comes from a small speaker on his desk. His personal computer, which he calls Lee, replies,

"Today is not busy for a Monday. You are oncall until noon. You have 17 cases to review and report on. There is a slide conference with the residents at 4:30 and you have autopsy service."

"Okay, I'll read my mail first, then start on the cases, beginning with the dull ones. I want to finish my manuscript today, so check the library for recent papers that match my breast cancer interest profile."

Dr. Jones starts to review tissue specimens. While he examines the three-dimensional electron micrographs on his monitor, Lee recites a brief history of the patient and the particulars of the operation. The slides are digitized versions of the image stored in the computer. Dr. Jones earmarks an especially interesting area to illustrate a point to the senior residents in the afternoon by circling the portion on the screen with his finger.

Dr. Jones dictates a report which Lee types and codes. If Lee doesn't know how to classify elements in the report Lee asks Dr. Jones to supply them. In one case, Dr. Jones is doubtful of his tentative diagnosis. He has Lee call the surgeon who is located in the operating theatre and the patient's physician who is in his office across town. While they examine the same slide on their desk monitors, Dr. Jones asks Lee to display a decision making tree on their monitors and to assign probabilities to each of several options that they select. Using data from Dr. Jones' cooperative study, and from the journal literature for patients with similar pathologic and physiologic features, Lee computes the risk of recurrence and the expected survival for early and late recurrence. Dr. Jones and his colleagues decide on the therapeutic course.

Embedded in this scenario are these features: a variety of information formats are delivered and used interactively on the monitor; the system listens and responds intelligently; the system manipulates data and presents an analysis.

The corresponding features for using published information might include these: the use of text and images is selective and completely task oriented; anything displayed on the screen could be tagged for future use; the computer can recognize concepts, clusters of words, and search the literature databases that exist; the computer can compile a bibliography of the materials that Dr. Jones has consulted and plans to use in his paper, and it can display the citation indexing map for those documents. Thus Dr. Jones could be alerted to the existence of related new materials or new research areas. In preparation for a consultation on a particular patient, Dr. Jones could have the library computer identify publications that his collaborating colleagues had tagged as useful, and it could relate paragraphs or data to selected patient records.

Now to return to November 29, 1983. Disraeli once told the students of Glasgow University that two kinds of knowledge were necessary for success in life. The first was self-knowledge. The second was knowledge of the spirit of the age. That did not mean, he said, that one must follow that spirit; it might be necessary to resist it, but it was essential to know the spirit of the age in which one lived and acted.'

The spirit of this age is high technology combined with individualized and personalized response, what John Naisbett 
calls hi tech/hi touch. It is multioptioned. There was a time not long ago when telephones from one source came in one shape and only one color and did only one thing. The age is entrepreneurial, decentralized, and self-reliant. We already see the effects. Universities and colleges no longer have a monopoly on postsecondary education. More adult learners are leavening the student body. The demand is for shorter, more focused training programs. Universities are wiring together networks to improve the transfer and management of information. Students are being required to own microcomputers and expected to become competent in using information technologies and sources, including campus electronic mail, word processing, and library databases. A number of universities have responded to the deregulation of AT\&T by purchasing telephone systems instead of leasing services. This puts them in the telecommunications business.

What must be the library response? One response is that libraries and librarians must become problem-oriented: not library problem-oriented, but user problem-oriented. If we can shift to this perspective, any fears about the existence of meaningful work in the future should evaporate. We must move toward creating newer campus information dissemination systems. We must engage in campuswide planning for integrated systems of locally useful information. This is something no vendor can do for us. We must insist that our institutions work with us and with publishers to design an overall systems solution to the creation, management, and delivery of text and bibliographic information.

The research libraries and the university faculties in this country constitute a reservoir of knowledge on which society generally will come to depend more and more. By the year 2000 more than half of the population will be aged fifty-five and older. Nearly all of us here will be there, and we will be a great deal more demanding of libraries and less tolerant of their limitations than we are now. It would not be surprising for libraries to take on curatorial responsibilities for digital databases and files, to have educational responsibilities for continuing education in information base management, to meet the faculty member's need for personally responsive information support suggested by Panko's scenario, and to have intelligently coordinated the library's multiple databases with the databases used in teaching, practice, and learning.

Consider this day in the life of a reference librarian in 1997. You log into your personal work station in the information service office. You see an array of library databases and the record of their uses during the last eight hours. You decide to check on the business module and select a transaction at random. The record shows that a junior business major with a $\mathrm{C}$ - average had logged in looking for material that will help him write a paper on the factors in the early 1980 s that led to the decline of management information systems. The system had prompted him to state a tentative thesis, then it asked a series of questions to find out what key names and words he had in mind to find more about. The system responded with an array of recommended readings, calibrated to his level of course performance, and the materials were identified earlier by faculty in the department who teach the course. The student scans some of the material on immediate retrieval and downloads some text. Some material is not retrievable without a later search of back files. The student logs off without requesting a back-file search. You are not responding to the query but reviewing the way in which the library information system handled the transaction in order to improve on the design of the system. You don't know this, but the student submitted his paper via electronic mail and earned a $C$ - because the faculty member ran a word-count check and found the student had only strung together sentences without modification or attribution, instead of developing an analysis.

Does this seem fanciful or frightful? No matter, write your own scenario for 1997. The important thing is to write one, to conceive of different ways to enhance the utility of our major assets, to improve the productivity of the academic community. 
We all understand that the time has passed for building definitive collections of books and materials. But we seem to be engaged in compiling definitive collections of bibliographic data instead. We must question whether an unqualified list of bibliographic citations is responsive in an educational or problem-solving environment like a university. As time goes on, and people gain more familiarity with databases and other information sources, the realities of time and economics will exert great pressures on libraries to provide data that are problem specific. The following opinion of one of our major assets, MEDLARS, may not be uncommon.

Libraries are repositories for information that may or may not survive the test of time and that may or may not have some ultimate practical or even theoretical value.... Although a computerized information system such as MEDLARS may be suitable for certain applications, the capacity for storing, retrieving, and transmitting all possible information bearing on questions . . . is of trivial importance compared to the task of obtaining credible answers themselves. Where resources are in short supply they should be used for obtaining answers to important questions rather than for processing information of dubious or ephemeral value..$^{10}$
This statement can leave no doubt as to what we should expect from the future. The opportunities arrayed before us now appear exciting and multivarious. It is still unclear who will own, operate, or control the electronic information delivery systems that will serve academic centers ten or twenty years from now. There are opportunities for creative entrepreneurship for professional associations, university systems, and libraries. If universities can go into the telephone business, and if libraries are getting in the bibliographic database business, perhaps they might well consider whether they shouldn't be in the information delivery business.

Some of you must make a career of planning and designing the integrated information systems that universities and colleges are becoming. More institutions, in addition to Carnegie Mellon, must take leadership and move into the second stage of technology adoption and start doing different things in different ways. Perhaps the University of Illinois at Chicago, with its record of innovation and its outstanding leadership, will breach the gap between what is and what could be, for the good of us all.

\section{REFERENCES}

1. M. Mack, "The Life of Learning," ACLS Newsletter 34, no.1/2:2-15 (Winter-Spring 1983).

2. N. W. Matheson and J. A. D. Cooper, "Academic Information in the Academic Health Sciences Center: Roles for the Library in Information Management," Journal of Medical Education 57, no.10: part 2 (Oct. 1982).

3. P. Drucker, Managing in Turbulent Times (New York: Harper, 1980), p.43-45.

4. G. Harmon, Human Memory and Knowledge; a Systems Approach (Westport, Conn.: Greenwood, 1973), p.119.

5. R. Taylor, The Making of a Library (New York: Wiley, 1967).

6. 'With Presidential Candor,' Johns Hopkins Magazine 34, no.5:30-36 (1983).

7. L. Fleischer, "Talk of the Trade," Publishers Weekly 224:63 (Nov. 4, 1983).

8. W. Panko and A. Gorry, "Pathology through the Looking Glass," The Pathologist 37:463-70 (July 1983).

9. H. Fairlie, "The Vanity of Vanity Fair,"' The New Republic 3557:25-30 (Mar. 21, 1983).

10. K. White, "Information for Health Care: An Epidemiological Perspective," Inquiry 17:296-312 (Winter 1980). 